\title{
CATEGORIA, TEORIA, CONCEITO (PARA DIZER O SER EM MÚLTIPLOS SENTIDOS)
}

\author{
CATEGORY, THEORY, CONCEPT (SAYING TO BE IN MULTIPLE SENSES)
}

Lílian do Valle ${ }^{1}$

Resumo Qualquer que seja o ponto de partida dessa experiência que se denomina pensar, seu desenvolvimento e efetividade tomam a forma de uma manifestação. Como não há manifestação sem espectador, o pensamento depende, pois, do outro a quem ele se endereça: nem que, precária e temporariamente, eu seja para mim mesmo a figura desse outro. Assim, se os humanos são 'feitos de mundo', o pensamento humano é feito das palavras que, engendradas nesse e por esse mundo, fornecem, por sua vez, ao mundo os sentidos que o fazem ser para nós. Assim, talvez uma das primeiras tarefas da reflexão filosófica da educação seja a de contribuir para o questionamento dos sentidos e das torções de sentido a que os modismos, ou a simples rotina, submetem as palavras: neste artigo, entre tantas ocorrências que se poderia invocar, interessou examinar a noção de 'categoria', cuja trajetória parece especialmente ilustrativa dos riscos a que o uso dogmático pode submeter a reflexão.

Palavras-chave filosofia da educação; categoria; pensamento.
Abstract No matter what the starting point for this experience called thought, the development and existence of thought take on the shape of an event. Just as there cannot be an event without spectators, a thought depends on the person to whom it is addressed; even if precariously and temporarily, I become, for myself, the figure of this other person. Thus, if human beings are 'made of the world,' human thought is made of words which, created in and by this world, lead, in turn, to the world of meanings and what they signify to us. As such, perhaps one of the first tasks of philosophical reflection on education is to contribute to questioning the meanings and distorsions of meaning that trends, or simple routine, impose on words. In this article, among the many occurrences that could be mentioned, the goal was to examine the notion of 'category,' the path of which seems to be especially illustrative of the risks that dogmatic use can impose on reflection.

Keywords philosophy of education; category; thought. 
Uma categoria não é uma coisa qualquer; em filosofia, é [algo de] tão rigoroso quanto uma noção científica em outro domínio.

G. Deleuze (1978)

Em que pese a grande pregnância da imagem de uma atividade muda e desencarnada, a experiência do pensamento ensina que pensar é pensar 'com' palavras; mas, não sendo as palavras símbolos neutros, já que sempre acabam por incorporar os sentidos que deram a conhecer, pensar também é, paradoxal e constantemente, pensar 'contra' as palavras.

Pensar é, primeiramente, pensar 'com' as palavras: se de fato podemos afirmar, como lindamente o fez Hannah Arendt, que os viventes são 'feitos de mundo', então é igualmente possível sustentar que, por termos as palavras, nós, os humanos, mais do que qualquer outro vivente, somos constituídos de e pela 'mundanidade', de e pela existência de um mundo comum: no qual todos habitamos (Arendt, 1981, p. 38), pois de palavras é constituído o que é para nós o mundo; e tanto quanto a idéia de uma 'linguagem privada', a depender inteiramente de uma convenção estabelecida entre o sujeito e ele mesmo é absurda, da mesma forma o que podemos denominar de 'mundo privado' constitui-se contraparte necessária e isogênica do que fazemos ser para nós como mundo compartilhado.

Mas devemos ir mais longe: são os outros a garantir, diz Arendt (1981), a 'objetividade' de cada existência individual - embora tão freqüentemente possa parecer, como ocorreu a Descartes, que o simples sentimento que o indivíduo tem de sua existência é suficiente para enraizá-lo na vida (...). Nisso, aliás, consistiu o famoso cogito ergo sum cartesiano: em prolongar a certeza do instante pleno, mas breve e fugidio, do qual se apossa de forma imediata o pensamento, em garantia irrefutável da existência individual. Opondo-se a esta noção, que serviu de base para que o indivíduo moderno se pensasse um ser isolado em sua razão, independente não só de seu tempo e de sua sociedade, mas até de sua experiência corpórea, Arendt (1981) afirma a impossibilidade de ancorarmos nossa existência na pura subjetividade:

Os seres vivos são a tal ponto 'feitos de mundo' que não existe sujeito que não seja, igualmente, objeto e que assim não apareça ao outro, que garante sua realidade 'objetiva'. O que denominamos habitualmente 'consciência', o fato de eu tenha também o sentimento de mim mesmo e possa, pois, em certo sentido, aparecer a mim mesmo, não seria jamais suficiente para garantir a minha realidade. O Cogito me cogitare ergo sum de Descartes não é uma proposição lógica pela simples razão de que a res cogitans jamais aparece sem que essas cogitationes se concretizem em 
linguagem falada ou escrita prevista para um auditor ou um leitor (Arendt, 1981, p. 38, tradução nossa).

Assim, qualquer que seja o ponto de partida dessa experiência que denominamos pensar, seu desenvolvimento e efetividade exigem a passagem à discursividade, se 'concretizam' sob a forma de uma manifestação lingüística$^{2}$. A 'palavra' autêntica é 'idêntica' a pensamento, afirmava MerleauPonty: ela é a outra face do pensamento, que por ela se faz comunicável aos outros e a si mesmo; ela é o pensamento como expressão.

Assim como não se poderia estabelecer a linguagem por convenção, também não se poderia convir consigo próprio de estabelecer ex nihilo uma linguagem do pensamento puro que nada devesse a nada... só é possível pensar à condição de se haver recebido uma linguagem (Castoriadis, 1982, p. 137).

Castoriadis comenta, ainda, que a idéia da convencionalidade da linguagem, tornada tão corrente, costuma se fazer acompanhar de, pelo menos, duas grandes falácias: a primeira, a idéia de que essa convenção se estabeleceria em lugar e tempo precisos, por meio de um gesto igualmente preciso; mas, assim como sua 'autoria' não pode ser precisada, devendo ser imputada ao que o autor denominava 'coletivo anônimo', da mesma forma é impossível fixar o 'lugar' em que o pacto original da linguagem se realizou, ou um momento anterior à linguagem, que pudesse ser apresentado como sua origem; como tampouco se poderia isolar o 'gesto' que deu origem à convenção. A segunda falácia denunciada é a de que a convenção se sustenta por ela mesma, não estando apoiada senão sobre a pura convenção. Mas não há 'pura convenção', assim como não há um 'fora da convenção'. A crítica visa, pois, por um lado, a ontologia herdada, para a qual tudo que é se apresenta como determinação, para qual tudo na história tem sua origem em uma coisa (como, p. ex., um evento climático), em uma idéia (como, p. ex., o progresso) ou em um indivíduo ou grupo de indivíduos que podem ser inteiramente determinados; por outro, à falsa oposição entre indivíduo e sociedade, marcada pela mitologia de uma natureza anterior à sociabilidade.

É, pois, nossa existência, ela própria que, até em seu sentido mais 'privado', depende do mundo comum, fornecedor da matéria de da qual é feita a discursividade de nosso pensamento e sua manifestação; e como não há manifestação sem expectador, o pensamento depende, em particular, do 'outro' a quem ele se endereça: nem que, precária e temporariamente, seja o próprio indivíduo a figura desse outro. Assim, se os humanos são 'feitos de mundo', o pensamento humano é feito das palavras, as quais, engendradas nesse e por esse mundo, fornecem por sua vez ao mundo os sentidos que o fazem ser para nós. 
Logo, o que podemos, tão freqüente e indevidamente, apresentar como 'subjetividade' desse pensamento - o fato de que ele possa expressar a singularidade de um sujeito pensante, não implica, como nos habituamos a imaginar, em sua incomunicabilidade; pelo contrário, é a aparição dessa singularidade que se deixa implicar da possibilidade de comunicação, da possibilidade de a linguagem se constituir em realidade, antes de mais nada, para o próprio sujeito. A subjetividade só existe e se manifesta como discurso, pela palavra que insinua no vazio da divagação, a uma só vez, o domínio público e a experiência privada. Nessas circunstâncias, o pensamento depende de uma cadeia de decisões de sentido sob forma de palavras e relações entre palavras. Por isso, pensar é pensar 'com' as palavras.

Entretanto, exatamente porque são públicas, e estão inseridas em uma cultura e uma história, as palavras sempre carregam muito mais do que o puro símbolo: elas são sentido instituído, nunca vêm soltas, são como "partes que, arrancadas do todo, trazem junto suas raízes" (Castoriadis, 1982, p. 143). As 'raízes', nesse caso, não são necessariamente a origem etimológica, mas, igualmente, significados que às palavras vão colando em seus diferentes usos, e, não raro, acabam por lhes acrescentar um número indefinido de novas acepções - embora por vezes tenhamos a impressão de não haver, entre as palavras disponíveis, símbolo adequado para significar o que pretendemos. No dizer de Cornelius Castoriadis, entre as palavras e os significados, entre o símbolo e o simbolizado, há sempre excesso e carência: “Há (...) não só supradeterminação, mas também e ao mesmo tempo sub-determinação do símbolo - assim como há, ao mesmo tempo, supra-simbolização e sub-simbolização do simbolizado" (Castoriadis, 1982, p. 50).

Por isso, pensar é também pensar 'contra' as palavras3: contra o exagero ou a penúria dos sentidos que veiculam, contra o que nelas é imprecisão ou, ao contrário, significação reificada, fechada, dogmatizada. Contraditórios ou complementares, redundantes ou inaccessíveis, os significados que dão vida às palavras as desgastam pelo uso reiterado, assim como pelo esquecimento. Nesse sentido, pensar é tanto escolher quanto recusar palavras e, por meio delas, eleger sentidos, tanto quanto expurgá-los. Ocorre, porém, que o desgaste produzido pelo uso descontrolado de uma palavra não se dá apenas pela perda de sua força expressiva, pelo fato de que a ela passam a ser somadas múltiplas significações; em muitos casos, como os discursos na área de educação exemplificam, o recurso abusivo a uma palavra, ou noção, acarreta em tal engessamento de um significado que, sem sua crítica, o pensamento se imobiliza e pára.

Assim, talvez uma das primeiras tarefas da reflexão filosófica da educação seja precisamente a de contribuir para o questionamento dos sentidos e das torções de sentido a que os modismos ou a simples rotina submeteram um termo: nesse artigo, entre tantas ocorrências que poderíamos invocar, 
interessou-nos examinar a noção de 'categoria' - que, por muitos dos usos a que se prestou, acaba por ser especialmente ilustrativa dos riscos a que o uso dogmático pode submeter a reflexão.

Porque, por um paradoxo que nada tem de casual, essa noção retraça, em sua longa trajetória no terreno filosófico, a história das tentativas de se lidar com a polissemia da experiência humana - para conjurá-la ou para dela extrair a própria seiva do pensamento - ela parece especialmente apropriada à reflexão sobre a prática da educação, pois aí, tanto quanto na prática da psicanálise e da política, estando em jogo a autoformação, a singularidade irredutível do humano impõe um pesado desafio à teoria que, cumprindo sua vocação para a universalidade, muitas vezes constrói lindas formalizações que tanto nos atraem, e, entretanto, não cessam de afugentar o sujeito empírico que é o próprio fim de toda reflexão, sendo o único que encontramos e supostamente pretendíamos conhecer. Buscando escapar ao triste destino que é o da perda de seu objeto, a teoria tende outras tantas vezes para o extremo oposto: passa então a pretender que só lhe interessa a existência particular de seu objeto e, para melhor mantê-lo sempre junto a si, passa a rejeitar todos os traços que o ligam a outros. Mas, assim agarrada ao objeto empírico, a teoria perde sua alma, que é a discursividade. Reduzida à mera descrição, a teoria emudece.

Esses dois limites extremos da falência da atividade teórica estão já presentes no contexto em que se originou a noção de 'categoria'. Sem dúvida devido à tradição democrática, a marca da pluralidade está a tal ponto etimologicamente associada ao termo, que ele não encontra lugar no vocabulário platônico: com a teoria da participação das essências, Platão dissolve qualquer pluralidade em um sentido único e total da existência, que é, inatingível às palavras; e que, em Aristóteles, dá origem a uma das muitas aporias que definem a grandeza da reflexão do filósofo.

Em sua acepção original, o conceito de categoria nos lembraria dos limites constituintes do nosso dizer e do nosso pensar sobre a realidade da existência. Como, então, a noção - nascida, exatamente, da impossibilidade do discurso único, assim como das exigências da palavra compartilhada, não somente acaba por designar, na história da filosofia, características universais do entendimento privado (Kant) como, por influência de certa tradição marxista, passa a servir a uma verdadeira reificação conceitual?

Decerto, a instituição de uma noção abstrata de 'trabalho', capaz de unificar em si toda uma multiplicidade de experiências relacionadas à produção material da vida, não é iniciativa de Marx, mas, antes, uma instituição social, exigida pelo modo específico de organização da produção moderna, como base para as trocas mercantis, para a mensuração e para a venda da força de trabalho livre. Nesse sentido, a 'centralidade do trabalho' é uma invenção liberal, e a subsunção de todas as atividades sociais àquelas 
que visam à reprodução das condições materiais de existência, longe de ser um posicionamento teórico, corresponde a uma estratégia do capitalismo. No entanto, tornar o trabalho uma referência para pensar a "atividade humana de todos os tempos" (Gollain, 2001, p. 177), estabelecer a 'categoria trabalho' como estalão pelo qual tudo deve se medir e se reduzir é uma decisão teórica de grandes conseqüências, que não pode ser debitada unicamente ao avanço da visão liberal de mundo.

No entanto, não é também esse o único caso em que o recurso à denominação 'categoria', longe de lembrar a parcialidade do ponto de vista sustentado e, portanto, a necessidade de periódica revisão dos limites do próprio discurso, torna-se uma espécie de salvo-conduto para o discurso dogmático e único.

\section{Origens}

Em seu sentido grego primitivo, kategoría provém do verbo katégorein, que significa 'acusar'. Tal emprego parece acomodar-se bem às raízes etimológicas da palavra, onde ressoa a referência à praça pública, à ágora ${ }^{4}$, onde se 'fala publicamente' 5 , pois a acusação é palavra pronunciada diante de uma autoridade, diante da coletividade ou de seus representantes. Não se trata, pois, como veremos adiante, de mera coincidência: nessa tradição do mundo grego antigo inventor da democracia, e, diferentemente do sentido que receberá da modernidade kantiana, a categoria implica em uma pluralidade de perspectivas, as quais só a participação igualitária e a liberdade de expressão características do espaço público engendram. Tal como a idéia de acusação, até hoje ligada à presença de um corpo de jurados a quem a denúncia é dirigida, a fim de ser examinada, a categoria é uma atribuição pública de sentido que clama por uma confirmação igualmente pública (Chantraine, 1999; Bailly, 2000).

Este é, pelo menos, o fundamento do 'gênero judiciário', ou do discurso político: a necessidade de um terceiro, de uma testemunha, indivíduo ou grupo - não por acaso, um recurso que Platão sempre recusa com veemência, no que se refere à busca filosófica da verdade (Platão, Górgias, 1942, 471 e - 475 e ; Platão, República, 1989, I, 348, a-b ; Lyotard, 1983, p. 43).

Assim, afirmada pela tradição democrática e rejeitada pelo platonismo, aos poucos a acepção meramente jurídica é ultrapassada, e a palavra ganha o sentido mais amplo, até passar a designar de forma bastante genérica a 'atribuição' - uso definitivamente fixado por Aristóteles, que recorre ao termo para significar o ato de imputação de uma qualidade a um sujeito, ou mesmo para designar o próprio atributo que se associa a algo ou alguém. Desta forma, na tradição filosófica, a categoria é o que se 'predica', o que se 
diz de algo ou de alguém; mas o termo também serve para indicar as diferentes possibilidades de qualificação, ou os 'modos de predicação' (Aubenque, 1980, p. IX).

'Modos de predicação': maneiras diferentes de falar de algo, de buscar exprimir o que é objeto de nossa atenção e exame, de definir aquilo sobre o que falamos. Isso, é claro, pode soar aos ouvidos contemporâneos como uma evidência, a tal ponto estamos absolutamente acostumados à idéia de que para tudo sempre há diferentes perspectivas, as quais introduzem diferentes definições do objeto examinado. Mas, como a metáfora da visão bem dá a entender, na maior parte do tempo essa familiaridade se restringe apenas a uma 'idéia', à aceitação 'formal' de que só vemos através de uma perspectiva que nunca é, nem total, nem a única possível; pois, na prática, nosso ângulo de visão sempre nos aparece como (...) a visão inteira. Como jamais vemos as fronteiras de nosso campo visual, acabamos por nos esquecer de sua existência: e é por isso que como comenta Merleau-Ponty (1999, p. 28) "a visão mais mascara a subjetividade do que a revela".

Nós construímos, pela ótica e pela geometria, o fragmento do mundo cuja imagem pode formar-se a cada momento em nossa retina. Tudo aquilo que está fora desse perímetro (...) não age sobre nossa visão (...) Deveríamos, portanto, perceber um segmento do mundo contornado por limites precisos, envolvido por uma zona negra, preenchido sem lacunas por qualidades, apoiado em relações de grandeza determinadas como as que existem na retina. Ora, a experiência não oferece nada de semelhante e nós nunca compreendemos, a partir do mundo, o que é um campo visual. (...) Não é fácil descrever a região que rodeia o campo visual, mas é certo que ela não é nem negra nem cinza. Há ali uma visão indeterminada, uma visão de não sei o quê e, se passamos ao limite, aquilo que está atrás de nós não deixa de ter presença visual (Merleau-Ponty, 1999, p. 26-27).

Estando limitados a uma perspectiva necessariamente segmentária da realidade, o que deixamos de ver não é apenas a 'totalidade', aliás, sempre virtual e inacabada, de todos os segmentos de mundo possíveis, mas, para começar, os próprios limites de nosso campo visual: é nesse sentido que 'não ver' é parte integrante da experiência de ver alguma coisa.

O que vale para a visão vale, igualmente, para o pensamento: os 'fragmentos de mundo' tendem a nos aparecer como fragmentos totais, porque em certa medida essa é a condição para que se tornem para nós provisoriamente inteligíveis; porém, o apego à 'aparente inteireza' de nossa perspectiva conduz à negação de outras perspectivas e, finalmente, à naturalização dos nossos limites. 


\section{Dizer o ser em múltiplos sentidos}

No entanto, afirmar que é possível dizer diferentes tipos de coisas acerca de um mesmo objeto é, até certo ponto, levantar o paradoxo da comunicação, que assim poderíamos resumir: para que haja comunicação, e não apenas mal-entendido, é forçoso que haja entre dois ou mais interlocutores ao menos uma referência comum; mas, para que a comunicação não se dissolva no vazio da reiteração, é preciso haver um ou mais deslocamentos impostos a essa referência mínima pelas perspectivas das partes.

Pretender suprimir, no diálogo, todas as perspectivas, salvo aquela que, a partir de então, se apresenta como única visão possível, que não admite deslocamentos, é trocar a busca do conhecimento pelas certezas do totalitarismo. “Em regra geral, um objeto que é pensado sob a categoria do todo (ou do absoluto) não é um objeto de conhecimento (...) Chamar-se-ia de totalitarismo o princípio que afirma o contrário" (Lyotard, 1983, p. 18, tradução nossa).

Esse totalitarismo pode ser afirmado de forma absolutamente consciente - como é o caso dramático dos regimes em que o dogma religioso ou político exerce a função de autoridade incontestável, silenciando qualquer possibilidade de dissidência, ou, mais sutilmente, nos meios acadêmicos, sob a forma legitimada de 'luta por hegemonia teórica'. Contudo, de forma mais ampla, é preciso reconhecer que ele habita, em germe, o conformismo de cada um de nós.

A 'perspectiva do todo' que Jean-François Lyotard denunciava é aquela que está em busca de um conhecimento que não esteja preso às limitações humanas, aos ângulos de visão. Se aquilo que nos aparece à visão é forçosamente limitado, a solução totalitária consiste em definir o nosso ângulo próprio como a única posição de observação legitimada e possível. Historicamente, essa posição se confundiu com a própria theoria e, muito mais tarde, com a ciência moderna, que fundou suas perspectivas em um 'além' que a tornava inquestionável e intangível: ao invés de se contentar com a crítica dos limites daquilo que simplesmente aparece à nossa visão, a ciência busca o enunciado único que permite a verdade. Um único enunciado por referente significa que só pode subsistir, para o discurso, uma categoria única - ou uma categoria 'organizadora' de todas as demais.

A ilusão da univocidade - que faz que, para cada objeto ou fenômeno, exista um e um só enunciado verdadeiro - é, por assim dizer, constitutiva da história do conhecimento. Dizer o ser de maneira unívoca é alcançar o conhecimento seguro, racional, científico, em uma palavra: inquestionável. Este é o projeto de Platão e, antes dele, de Parmênides. ${ }^{6}$

E é contra esse projeto que se ergue o pensamento de Aristóteles, não por acaso o filósofo, diferentemente de seu mestre Platão, não desprezou os 
testemunhos da sua tradição de pensamento, e buscou, até o ponto em que sua própria posição assim o permitia, colocar-se no lugar do outro:

O ser propriamente dito se diz em múltiplos sentidos: vimos que há o ser por acidente, em seguida o ser como verdadeiro e como falso; e, além disso, há as figuras de predicação, por exemplo o que, o qual, o quanto, o onde, o quando, e outros termos que significam dessa maneira. E há, além de todos esses sentidos de ser, o ser em potência e o ser em ato (Aristóteles, Metafísica, 1990, E, 2, 1026 a 33, tradução nossa).

De tudo que podemos dizer sobre algo, há certas coisas que não são necessárias à existência daquilo sobre o que falamos, embora a caracterizem: são os 'acidentes'. Há também o que dizemos e que corresponde, ou não, àquilo de que falamos - a 'verdade' e a 'falsidade' de nosso discurso; e há as circunstâncias, os ângulos, as perspectivas que adotamos para falar de algo. Mas todas essas possibilidades definem formas de predicação: e, assim, as categorias são os instrumentos para produzir uma afirmação que admitimos ser uma entre outras possíveis: "Pode-se, pois, reduzir a teoria das significações do ser à teoria das categorias e definir as categorias como sendo as significações do ser, na medida em que elas se constituem em discurso predicativo" (Aubenque, 2002, p. 172, tradução nossa).

Instituição humana, a linguagem deve, a princípio, servir-se de um número definido de palavras comuns para dizer os fenômenos, que são: sempre diversos e singulares; além disso, a linguagem é um meio de predicação que não fala jamais só das coisas, mas, a cada vez, das intenções que movem o dizer, do tipo de relação que se estabelece entre aquele que fala e a realidade. É isso que a reflexão de Aristóteles - esse "filósofo de uma honestidade terrível" (Cassin, 1999, p. 9) - contra ele próprio sugere. Pois não era essa sua intenção: o que pretendia era, muito pelo contrário, prevenir o pensamento contra os efeitos desses 'equívocos' que a língua naturalmente produz, sob a forma de símbolos (sempre) universais para dizer coisas (sempre) particulares - uma só palavra designando coisas diferentes (Aristóteles, 1989, I, 165 a 12); e, sobretudo, purgar o pensamento desse formidável equívoco que consiste em multiplicar as significações para uma só coisa7! Particularmente em seus confrontos com os sofistas, Aristóteles precisou lidar com o fato - e aí se situa talvez de forma mais límpida sua grandeza - de que a língua não cessa de produzir, para uma mesma coisa, com nome único, definições diferentes. Essa 'coisa com um só nome' para o qual ele sonhara uma só definição, ele a chamava de essência aquilo que se poderia dizer de forma segura sobre o ser. Em outras palavras, buscando eliminar as ambigüidades do ser, Aristóteles (o qual afirmava que significar mais de uma coisa é nada significar) nos fornece elementos 
para pensá-las e para, assim fazendo, superar seu próprio pensamento, pois, conforme comenta um de seus mais reconhecidos estudiosos, ao final de sua reflexão,

A ambigüidade do ser permanece (...) e em um duplo sentido. Para começar... longe de ser suprimida, a homonímia é transferida...: para além da essência, as categorias do ser não são mais, finalmente, do que múltiplas significações da ambígua relação com a essência. Em seguida, e, sobretudo, [sua doutrina] (...) pretendendo fundar a unidade do discurso sobre o ser, consagra o estilhaçamento desse discurso (...) o discurso humano sobre o ser não significa o ser senão de forma múltipla e sob o modo da dispersão (Aubenque, 2002, p. 197-198, tradução nossa).

São esses os ensinamentos da honestidade de Aristóteles, que podem ser tão úteis à reflexão sobre a prática da educação, e que apenas a ignorância e a intenção totalitária desprezam: é que a auto-estrada para a 'visão única' - do aluno, do professor, do método, da teoria educacional - para o 'discurso único' idealizado é sempre interrompida pelos desvios e pelos cruzamentos provocados (...) pelo pensamento dos outros. Ou pelo próprio pensamento, quando ele aceita se fazer outro.

Apenas aqueles que, como Platão, insistem em reduzir ao silêncio tudo o que não lhes é assemelhado podem por essa estrada navegar sem embaraços maiores - além, é claro, de sua própria coerência.

\section{Conceitos, categorias, universalidade}

Aristóteles identificava, na comunicação humana, um problema capital: defrontados com a infinita diversidade da experiência, só temos para pensá-la (para comunicá-la) um número limitado de palavras. Assim, para ordenar a diversidade - para, por assim dizer, acolhê-la, recorremos a conceitos já instituídos, que definem eles próprios uma pluralidade de significações já determinada (Aristóteles, 1990, Z, 15, 1040 a 11). Se geralmente isso é o bastante, não é por outra razão além do conservadorismo de nosso pensar, que se faz, pois, mais 'com' as palavras do que 'contra' elas. No entanto, ali onde a atividade do pensamento se instala como exame e questionamento abertos, ela forçosamente implica na crescente necessidade de atribuição de novos significados para esses mesmos velhos conceitos; e, nesses casos mais extremos que definem a grandeza da reflexão humana por sua capacidade de ir ao encontro da diversidade do mundo, ela implica na criação de novos conceitos - a serem, por sua vez, instituídos e consumidos no uso e pelo uso que recebem. 
A noção de categoria introduz, porém, na história da filosofia, uma outra dificuldade: é a pretensão de se fixarem de uma vez por todas e antecipadamente formas universais, conceitos válidos para definir os 'modos' de dizer e de pensar tudo o que é. "O que se denomina uma categoria é um predicado - ou atributo - universal. Isso é, um predicado que se atribui, ou se predica, ou se diz de todo objeto" (Deleuze, 1978, tradução nossa).

Nisso consistiria a diferença canônica entre categoria e conceito: a exigência de universalidade. Categoria e conceito são instrumentos para pensar, para dizer, para determinar o que existe ou a experiência que fazemos daquilo que existe. Os conceitos têm a função de unificar um número indefinido de objetos ou fenômenos em um conjunto, tornando-os inteligíveis para nós. Ao fazê-lo, é claro que definem também, o que estará excluído desse conjunto, o que não estará submetido às determinações que atribui ao conjunto, o que ficará de fora da predicação.

Os conceitos atuam, assim, de forma a absorver a multiplicidade que experimentamos empiricamente e organizá-la. Trata-se, é certo, de uma interrupção sempre provisória e limitada da diversidade empírica. Provisória, porque submetida ao instante, ao agora; limitada, porque deixa de fora tudo o que o fenômeno considerado não abrange, e tudo que, tal como considerado nesse instante, ele deixou de abranger. Os conceitos fornecem, assim, um 'recorte' a que se submete a realidade. Contendo a marca do caráter parcelar de nossa experiência, os conceitos são múltiplos e sempre tributários daquilo a que se aplicam.

Tal como os conceitos, as categorias correspondem a uma unificação da experiência (Kant, 1980, p. 139): no entanto, as categorias são como uma promoção dos conceitos, pois o que se espera que elas definam já não é um conjunto particular de experiências, ou uma classe específica de fenômenos: pretende-se que as categorias sejam determinações universais, isto é, formas gerais de se determinar validamente qualquer experiência e qualquer fenômeno que possamos experimentar ou conceber.

O que é uma categoria? Uma categoria não é uma coisa qualquer; em filosofia, é [algo de] tão rigoroso quanto uma noção científica em outro domínio. O que chamamos de categoria é um predicado - ou, se assim se preferir, um atributouniversal. Isso é, um predicado que se atribui, ou se predica, ou se diz de todo objeto (Deleuze, 1978, tradução nossa).

Mas o que, dada a enorme diversidade da experiência humana, à qual justamente não paramos de aludir, corresponderia a esses modos de predicar que não aceitam exceções?

A resposta fornecida por Kant seria: nada, absolutamente, que venha da própria experiência - posto que ela é justamente o particular, o diverso, 
ela é aquilo que pretendemos predicar, que queremos determinar. A ruptura provocada pela aparição da diversidade nos permite reconhecer o tempo, sob a forma de um antes e um depois. Mas, tal como a experiência, que não se realiza fora do tempo, não haveria igualmente condições para o pensamento?

As categorias têm esta singularidade de serem conceitos que não nos vêm da experiência, mas que lhe fornecem um enquadramento a priori, por meio do qual ela atinge a um grau mínimo de organização e de inteligibilidade (Aubenque, 2002, p. XII, tradução nossa).

As categorias corresponderiam, então, a condições mínimas de organização necessárias para que possamos conhecer os fenômenos, fornecendolhes inteligibilidade. Não se pode pensar uma coisa sem que ela esteja minimamente delimitada: à 'essência' singular, como afirmava Aristóteles, ou à unidade, como dizia Kant. Logo, as categorias estão estritamente relacionadas à possibilidade de entendimento; elas não vêm 'da' experiência, mas têm já que estar presentes para que a experiência possa ser conhecida como tal.

Todo objeto não é um leão, todo objeto não é vermelho, mas todo objeto tem uma causa, todo objeto é um, todo objeto é uma multiplicidade de partes etc. Os predicados que se podem atribuir a um objeto qualquer são as categorias do entendimento, são os conceitos do entendimento (Deleuze, 1978, tradução nossa).

O problema está em saber o que fundamenta e legitima esta lista de propriedades permanente de tudo que podemos conhecer. Para afirmar condições universais para o entendimento, tanto Aristóteles quanto Kant deverão supor, ao menos, que à diversidade da experiência sensível se opõe a regularidade de uma essência ou de uma organização a priori, 'coisas em si' que resistem a qualquer 'manifestação', que não se manifestam, mas permitem que haja, para o humano, o que chamamos de manifestação.

Cedo se levantará a suspeita de que Kant universaliza e assim 'eterniza' indevidamente categorias que, de fato, estão historicamente ligadas a uma determinada organização teórica, que era a da ciência de seu tempo. Mutatis mutandis, a mesma suspeita, que jamais havia sido articulada até então, começa no século XIX a se levantar contra Aristóteles. Se as categorias não podem ser nem objetos de experiência nem logicamente deduzidas a partir de 'princípios', é possível que elas reflitam uma certa organização da linguagem (Aubenque, 2002, p. XII, tradução nossa). 
O problema é, pois, a universalidade. Supô-la na linguagem, numa organização necessária da linguagem - tal como alguns leitores de Kant fizeram e tal como na atualidade, para citar apenas um exemplo, Chomsky o fará - é uma atitude muito comum a partir da modernidade, mas não resolve em nada o impasse. E isso porque a existência de um modo de organização, de uma lógica universal a condicionar a linguagem de nada serviria se não condicionasse igualmente 'todo o real'. É preciso, pois, para que haja categorias, tal como as definem a história da filosofia,

(...) estabelecer explicitamente que as mesmas 'formas' ('gêneros supremos', para Platão; 'categorias', para Aristóteles e toda a filosofia ulterior) se encontram, valem ou são empregadas em todos os domínios do real e do pensado (Castoriadis, 1978, p. 226).

Essa é, segundo Castoriadis, a forma acabada do reducionismo lógico: supor que tudo - uma espécie viva, tanto quanto um sonho, uma obra arquitetônica, o movimento dos astros ou uma frase - pode ser tratado da mesma maneira.

Não se trata de negar os princípios da lógica elementar, que definem, por exemplo, que a condição para pensar ou para comunicar uma coisa é não admitir que ela seja, ao mesmo tempo, 'o que é' tanto quanto 'a negação' do que é; que definem, por exemplo, que para cada coisa existe uma causa. É preciso admitir que não se pode conhecer, determinar ou comunicar algo não definido como uma unidade: e 'unidade' é a primeira das categorias aristotélicas. Mas são duas coisas diferentes, constatar que certos princípios, ou 'categorias' são condições de inteligibilidade e propor que eles 'sempre' sejam, que para 'tudo' que existe (para todas as 'regiões do ser') eles sejam condições de inteligibilidade. Não é esse o caso: pois mesmo sobre a 'unidade' é possível afirmar que ela se diz multiplamente e conforme a realidade a que se aplica (...)

O que sobra, então, para as categorias? Seria decerto imprudente pretender negar que, para aquilo que se constituiu historicamente como atividade do pensamento, tanto quanto para a comunicação, permaneçam válidas certas condições. Além disso, a distinção entre conceitos e categorias permanece importante ali onde o pensamento e a discursividade se propõem a colocar em questão não apenas seus resultados, mas a própria atividade que os constitui e seus fundamentos: examinar tanto o que se diz quanto as 'condições' das quais necessariamente se parte para dizê-lo.

Ora, um dos primeiros questionamentos a que a categoria deve dar acesso é aos limites de validade que são os seus. Sendo estabelecidos na e pela cultura, esses limites são, até certo ponto, como afirmamos inicialmente, invisíveis para nós. Até certo ponto: é esta uma parte substantiva da batalha 
que o pensamento trava consigo próprio, para reconhecer o que lhe resiste sobre a forma de diversidade:

(...) as categorias são essencialmente multívocas, sua significação é co-determinada pelo que determinam. O que Aristóteles já tinha visto e dito a respeito do ser - que é um pollachos legomenon - (...) vale [também] para todas as categorias: 'um' e 'múltiplos', 'todalidade' e 'partes', 'substância' e 'reciprocidade' ... sua significação plena e operante é essencialmente diferente de uma região para outra (Castoriadis, 1978, p. 227).

'Existir' não significa, em toda parte, em todos os casos em que a palavra pode ser usada, a mesma coisa; o termo 'existência' designa uma pluralidade de fenômenos relacionados a uma diversidade de seres. Pretendemos examinar a existência humana, individual ou coletiva, e suas infinitas possibilidades, sua incontrolável diversidade. Como será possível fazê-lo?

(...) o fazer teórico humano é a descoberta e a exploração de regiões novas; só progride, portanto, conferindo significações novas às 'categorias' já disponíveis e, ainda mais importante, supondo-fazendo surgir 'categorias' novas. De tal sorte que qualquer intenção de constituir um verdadeiro 'quadro de categorias' (...) e, mais ainda, de 'deduzi-las' ou de 'desdobrá-las' em sua totalidade só pode ser, ou falaciosa, refletindo uma certa etapa de nossa relação teórica com o que existe (que erige como absolutos os resultados dessa teoria) ou então 'nominal e vazia', isso é, apenas descrevendo... [as predicações possíveis] no interior de uma linguagem determinada, acabada - e, portanto, morta (Castoriadis, 1982, p. 228).

\section{Teoria e singularidade}

Mas até que ponto a recusa da universalidade pode ir, quando se trata do pensamento, e até que ponto essa recusa pode ser constitutiva da atividade teórica? Aristóteles lembrava, com toda a razão, que em nosso pensamento jamais estão as coisas, e sim as representações das coisas. Se, de fato, não há pensamento sem linguagem, então é fato que não há pensamento sem uma certa universalidade - esta mesma, forçosamente introduzida pelo trabalho da representação e da simbolização. Não se pode, no entanto, derivar dessa exigência de universalidade a idéia de que as operações de representação e simbolização obedeçam a regras estritas, definidas aprioristicamente; muito pelo contrário, a conseqüência aqui é que a atividade de pensamento nos obrigará a colocar em questão, tanto quanto possível, as operações quase invisíveis pelas quais, ao examinar um fenômeno, estabelecemos 
uma representação, um símbolo, um conceito, recorremos a ele e persistimos em convocá-lo.

No entanto, no que se refere ao pensamento sobre a existência e, em particular, à teoria sobre o humano, a exigência da universalidade não se esgota aí, pois, como recordava Castoriadis, para lidar com seu objeto, decerto não bastará que a teoria se limite a afirmar reiteradamente sua singularidade: pois só o que daí resulta é, em primeira análise, uma simples e exaustiva 'descrição'. Mas, como não há pura descrição e, pela linguagem a simbolização já se estabeleceu, estabelecendo conceitos ou quase conceitos e suas relações, é forçoso o reconhecimento de que aquilo que o descritivismo finalmente produz jamais é (tal como ingenuamente supusera) o objeto singular, em sua particularidade: longe de lá, o que não cessa de produzir, de forma sub-reptícia e descontrolada, é o 'universal abstrato' do qual justamente pretendera fugir - esta forma sem conteúdo que se substitui ao pensamento e que se exime de toda prestação de contas teórica.

Mas, afinal, sobre o que é 'por si só' o indivíduo singular, sem que grama de universalidade lhes seja acrescentada, o que pode dizer a teoria? Nada. E isso, entre outras razões, porque o próprio, o singular, o particular não podem ser concebidos senão sobre o fundo do que é dado como coletivo, como comum, como universal. Repare-se que esse fundo é, entre outras coisas, a própria noção de tempo e de espaço: pois esse aqui e agora perseguido como o oposto do universal, o qual pretendemos conceber em sua singularidade, nada mais é do que o fenômeno extraído do tempo e eternizado nesse instante aqui - enfim, pura miragem.

Mas aceitá-lo não significa, evidentemente, rumar para o extremo oposto e negar a existência daquilo que só existe como particular, daquilo que é continuamente diverso. Voltamos, assim, ao problema com o qual se defrontara a honestidade de Aristóteles: só o que temos para dizer, o infinitamente diverso são as palavras comuns (...) (Aristóteles, 1990, Metafísica, Z, 15, 1040 a 11; Aubenque, 1962, p. 116). O indivíduo singular - esse mesmo cuja experiência que dele fazemos resiste às palavras - pelas mesmas razões resiste também à formalização que pretende lhe impor a teoria. Assim, o “(...) indivíduo propriamente dito será, então, o irredutível resíduo deixado por toda explicação (...)" (Castoriadis, 1982, p. 47).

Mas, atenção! Parar aí seria declarar sumariamente o óbito do pensamento discursivo, com sua exigência de se fazer público (comunicabilidade) e de prestação pública de contas (verificabilidade). Seria tomar o dogma como padrão único para o discurso. Seria interromper as condições de debate e de deliberação comum. Seria reduzir a linguagem, que não pode ser senão pública, a um uso sempre privado.

Desfazendo-se das quimeras que em sua história a filosofia inventou e manteve para seu conforto próprio, ao conceder à universalidade em que 
fundou suas certezas um caráter normativo e absoluto, a teoria sem dúvida está condenada ao destino de Sísifo: começar e recomeçar incessantemente uma atividade que jamais conhecerá fim.

Renunciando a seus sonhos de onipotência, a teoria aprende a aceitar que o singular sempre lhe resistirá, que o indivíduo permanecerá irredutível. Porém, a

(...) dificuldade é que, de direito, a teoria não pode reconhecer a existência de um tal resíduo como verdadeiramente irredutível; seu trabalho só tem sentido pelo postulado contrário (...) (Castoriadis, 1982, p. 47).

O que poderia ser esse postulado, além da insistência em desafiar a irredutibilidade da existência a fórmulas gerais? É por isso que, desfeitas duas poderosas ilusões: a de que há descrição - de que é possível o puro registro da singularidade; e a de que há para tudo explicação - pela qual cada particularidade pode ser reduzida a uma regularidade, a teoria é obstinada tentativa de buscar o que, "no indivíduo, o ultrapassa e nele representa o universal... [aquilo que], como termo ou como organização, vale para todos" (Castoriadis, 1982, p. 43).

E essa parece ser uma outra forma de dizer que, abraçando finalmente a sua provisoriedade como única forma de se ultrapassar, a teoria está livre para descobrir o que deve ao universal, ao qual deverá ainda voltar; mas, como jamais se volta exatamente ao que se deixou, a cada volta sua é uma nova teoria e novas possibilidades de elucidação que a cada vez se abrem para o enigma humano.

\section{Agradecimento}

Agradeço a interlocução de Giovane do Nascimento, doutorando do Programa de Pósgraduação em Políticas Públicas e Formação Humana da Universidade Estadual do Rio de Janeiro (PPFH/Uerj). 


\section{Notas}

1 Professora titular de Filosofia da Educação da Universidade do Estado do Rio de Janeiro (Uerj), Rio de Janeiro, Brasil. Doutora em Educação pela Universidade de Paris V. Pós-doutorado pelo Centre Louis Gernet (CNRS/EHESS), França (2002 e 2007). $<$ lvalle@uerj.br>.

Correspondência : Universidade do Estado do Rio de Janeiro, Faculdade de Educação, Departamento de Estudos da Subjetividade e da Formação Humana (DESF), Rua São Francisco Xavier, 524, sala 12.028, bloco B, Maracanã, Rio de Janeiro, Brasil, CEP 20.550-013

2 "A forma lingüística é (...) não apenas a condição de transmissibilidade, mas antes disso a condição de realização do pensamento" (Benveniste, 1966, p. 64).

$3 \mathrm{O}$ acordo perfeito entre o que a língua instituída põe à nossa disposição e o movimento instituinte do pensamento é, evidentemente, um fantasma e um mito. Resta-nos, pois, a tentativa sempre recomeçada de adequar essas duas pontas de nossa reflexão, que acaba por definir o próprio pensar. Mas é claro que a distância estabelecida entre os dois é tão maior quanto mais criativo e original for o pensamento. É nesse sentido que Castoriadis faz o elogio de seu mestre: “O que permite a Aristóteles escrever? 'É tanto o grego como o que o impele a desordená-lo': o que tem a dizer e que não poderá dizer, a não ser infligindo à língua uma torção inaudita, para escrever como nunca antes se havia escrito e como nunca mais se escreverá, 'pisando sobre a língua para levá-la além de si mesma'(...)" (Castoriadis, 1982, p. 149).

4 De kata (sobre, contra) + ágora (praça principal da pólis, mercado e também, por agorein, 'discorrer') (Chantraine, 1999).

5 Agoreuô: 'falar publicamente' (Cassin, 2004, p. 212).

6 "Se quisermos ouvir Parmênides enunciar ele próprio suas premissas, e em particular aquela que enuncia que, além do ser, não há senão não-ser e nada, o que é o mesmo que dizer que o ser se diz de uma maneira unívoca, encontraremos sua expressão nos seguintes versos: 'A primeira, a saber, que ele é (...) E permanece inexprimível'." Simplicius, Physique, 116, 25, Diels-Kranz.

7 “São ditas equívocas (homónima) as coisas que só possuem um nome em comum, ainda que as fórmulas que correspondem a esse nome sejam diferentes (...) Em revanche, são ditas unívocas (eunónima) coisas que têm em comum o nome e a fórmula correspondendo a esse nome idêntico" (Aristóteles, Categorias, I, 1 a $1-10$ ). 


\section{Referências}

ARENDT, Hannah. La vie de l'esprit. Paris: PUF, 1981.

A vida do espírito. Tradução de Antônio Abranches et al. Rio de Janeiro: Relume \& Dumará, 2000.

ARISTÓTELES. Les réfutations sophistiques. Tradução L.A. Dorion. Paris: Vrin, 1989.

. Métaphysique. Tradução J. Tricot. Paris: Vrin, 1990

Catégories. Tradução R. Bodeüs. Paris: Belles Lettres, 2002.

AUBENQUE, Pierre. Concepts et catégories dans la pensée antique. Paris: Vrin, 1980.

Le problème de l'être chez Aristotelis: essai sur la problématique aristotélicienne. Paris: PUF, 2002.

BAILLY, Anatole. Dictionnaire grec-français. Paris: Hachette, 2000.

BENVENISTE, Émile. Catégories de pensée et catégories de langue. In: Problèmes de linguistique générale. Paris: Gallimard, 1966, p. 63-75.

CASSIN, Barbara. Aristóteles e o logos: contos da fenomenologia comum. Belo Horizonte: Loyola, 1999.

Vocabulaire européen des philosophes. Paris: Seuil, 2004.

CASTORIADIS, Cornelius. Epilegômenos a uma teoria da alma que se pôde apresentar como ciência. In: . Encruzilhadas do labirinto I. Rio de Janeiro: Paz e Terra, 1982, p. 31-69.
O dizível e o indizível: homenagem

a Maurice Merleau-Ponty. In:

Encruzilhadas do labirinto I. Rio de Janeiro: Paz e Terra, 1982, p. 135-157.

CHANTRAINE, Pierre. Dictionnaire étymologique de la langue grecque: histoire des mots. Paris: Klincksieck, 1999.

CHOMSKY, Noam. Structures syntaxiques. Paris: Seuil, 1979.

DELEUZE, Gilles. Quatre leçons sur Kant. In: Synthèse et temps. Cours à Vincennes, 14/03/1978. Disponível em: $<$ www.webdeleuze.com/php/texte.php?cle $=58 \&$ groupe $=$ Kant $\&$ langue $=1>$. Acesso em: 10 ago. 2001.

GOLLAIN Françoise. Penser le travail dans son historicité. In: Recherches: Revue du MAUSS. Paris: La Découverte, 2001-2, n. 18, 176-195, p. 177.

KANT, I. Critique de la raison pure. Paris: Gallimard, 1980.

LYOTARD, Jean-François. Le différend. Paris: Minuit, 1983.

MERLEAU-PONTY, Maurice. Fenomenologia da percepção. 2. ed. São Paulo: Martins Fontes, 1999, p. 237-270.

PLATÃO. Gorgias. Tradução Croiset. Paris: Belles Lettres, 1942. République. Tradução Chambry. Paris: Belles Lettres, 1989.

Recebido em 05/05/2008

Aprovado em 22/06/2008 